\section{The effectiveness of surgery for congenital nystagmus}

The paper by Atilla, Erkam and Isikcelik in this issue investigates the effect of recessions of all four horizontal recti on 12 patients with congenital nystagmus $(\mathrm{CN})$. Since this procedure was suggested by Bietti and Bagolini ${ }^{1}$ rather limited improvements in visual function have been reported, despite some reduction of the $\mathrm{CN}^{2,3}$ The results of this latest paper are more encouraging as the authors find an improvement in visual acuity (VA) along with a reduction of $\mathrm{CN}$.

The gaps in our knowledge of $\mathrm{CN}$ present several interesting dilemmas; before deciding on surgery the patient's nystagmus needs to be carefully diagnosed.

\section{Nystagmus characteristics}

Accurate classification of nystagmus is important. If the patient has strabismus (stereoacuity is a useful indicator here, as small squints are difficult to observe in the presence of nystagmus) they should be carefully examined for the presence of manifest latent nystagmus (MLN). In MLN, the nystagmus fast phase beats towards the fixing eye and can be reversed by cover testing. Some cases of $\mathrm{CN}$ exhibit similar behaviour, and diagnosis will then rely upon eye movement recordings. The slow phase of $\mathrm{CN}$ has an increasing velocity whereas MLN shows decreasing, or constant velocity slow phases. Two further features of MLN are dissociated vertical deviation (DVD) and the absence of a true null zone - instead, nystagmus amplitude tends to damp when the fixing eye is adducted. Many patients with MLN have good vision, and surgical management is usually directed at correcting any strabismus.

Individuals with $\mathrm{CN}$ occasionally exhibit more than one null zone; this may be noticeable on testing acuity, but a more stimulating, dynamic stimulus (watching a video for example) will tend to bring out multiple null zones. The patient should also be observed for several minutes to check for periodic alternating nystagmus (PAN) where the null zone shifts with time. PAN is common in albinism ${ }^{4}$ and is easy to miss in $\mathrm{CN}^{5}$ The presence of multiple null zones or PAN may rule out null zone surgery.
Two salient features of $\mathrm{CN}$ complicate measuring the effects of treatment: the nystagmus increases when visual acuity (VA) is measured (thereby reducing VA), and VA tends to improve on repeat visits. Unfortunately, this may still catch some researchers unawares. Studies of $\mathrm{CN}$ treatments are strengthened by the inclusion of an untreated control group, or by having measures of visual performance over several visits before treatment, ${ }^{6}$ and by an analysis of eye movements. High-quality eye movement recordings not only aid the diagnosis of nystagmus but also allow potential visual acuity to be predicted ${ }^{7}$ and objective comparisons to be made.

The $\mathrm{CN}$ waveform contains periods when the eyes are moving relatively slowly. Individuals with $\mathrm{CN}$ maximise their acuity by placing their fovea at these 'foveation periods' where eye velocity is least. ${ }^{8}$ Subjects with albinism (who have no distinct fovea) behave in a similar fashion by consistently using a specific retinal locus ${ }^{9}$ corresponding to an area of retina that gives maximum vision. Such strategies suggest that ocular motor control can be precise despite the presence of $\mathrm{CN}$.

\section{Non-surgical options}

Any refractive correction that would be normally prescribed should be tried; VA may not improve in the clinic but patients benefit from their refractive correction in a more normal, relaxed environment if a clearer image reduces the 'effort to see'. Base-out prisms (with low minus lenses in pre-presbyopes) may help in cases with a strong reduction of $\mathrm{CN}$ on near viewing (it is the convergence, rather than the accommodation that is important ${ }^{10}$ ). Other therapies such as auditory biofeedback ${ }^{11}$ and cutaneous stimulation ${ }^{12}$ can reduce $\mathrm{CN}$ in some cases. BT therapy, which can be helpful in reducing oscillopsia in acquired nystagmus, has also been suggested for $\mathrm{CN}$.

\section{Surgery}

The goals of surgery for $\mathrm{CN}$ are to reduce the need for head postures by re-aligning the null zone, or to improve vision by reducing the nystagmus, or both.
Mr Jon Whittle Department of Ophthalmology and Orthoptics University of Sheffield Royal Hallamshire Hospital Glossop Road Sheffield S10 2JF, UK 
The Kestenbaum-Anderson procedure is an approach for the patient with an established null zone in eccentric gaze. The aim is to shift the null zone to primary gaze. Since the first reports, ${ }^{13-15}$ the suggested amounts of surgery have gradually increased in an attempt to reduce the chance of the head posture returning.

Bilateral recessions of both medial recti combined with a Faden suture (or Kestenbaum-Anderson procedure) have been reported to take advantage of a convergence effect. ${ }^{16}$ Caution should be exercised where there is potential to induce a divergent strabismus, particularly for near viewing.

Questions that have previously surrounded the type of surgery reported by Atilla et al. in this journal are that it may reduce conjugacy in eccentric gaze, which may limit benefits for those with an eccentric null zone. Subjects with a central null zone may be happy to trade reduced binocular vision in eccentric gaze if their $\mathrm{CN}$ waveform is improved following surgery. Any technique that reduces the effectiveness of extraocular muscles could affect fine ocular motor control. A simple measure such as saccadic peak velocity and accuracy could provide useful insights here. An interesting feature of Kestenbaum-Anderson surgery is a general dampening of the $\mathrm{CN}$ at all gaze angles, as well as a re-location of the null zone. ${ }^{17,18}$ Recent work on achiasmatic dogs with $\mathrm{CN}$ and see-saw nystagmus has demonstrated that the damping effect can be obtained by performing tenotomies without any resection or recession. ${ }^{19}$ This promising finding may deliver useful insights into the effects of surgery.

\section{Summary}

Many individuals with $\mathrm{CN}$ cope remarkably well. With several different surgical approaches available, there needs to be reasonable certainty that a chosen treatment is the best for an individual patient. It is hoped that continued research into the mechanisms underlying $\mathrm{CN}$ will deliver a deeper understanding of exactly how extraocular surgery brings about an improvement in some cases while still being less than perfectly reliable in others.

\section{References}

1. Bietti GB, Bagolini B. Traitement medicochirugical du nystagmus. Ann Ther Clin Ophtalmol 1960;11:269-96.

2. Von Noorden GK, Sprunger DT. Large rectus muscle recessions for the treatment of congenital nystagmus. Arch Ophthalmol 1991;109:221-4.

3. Helveston EM, Ellis FD, Plager DA. Large recession of the horizontal recti for treatment of nystagmus. Ophthalmology 1991;98:1302-5.

4. Abadi RV, Pascal E. Periodic alternating nystagmus in humans with albinism. Invest Ophthalmol Vis Sci 1994;35:4080-6.

5. Shallo-Hoffman J, Hesse CW, Tusa RJ. The incidence of periodic alternating nystagmus in motor congenital nystagmus. Invest Ophthalmol Vis Sci (ARVO Suppl) 1998;39: abstr 4180.

6. Evans BJW, Evans BV, JordahlMoroz J, Nabee M. Randomized double masked placebo controlled trial of a treatment for congenital nystagmus. Vision Res 1998;38:21932202.

7. Jacobs JB, Dell'Osso LF. An expanded nystagmus acuity function. Invest Ophthalmol Vis Sci (ARVO Suppl) 1998;39: abstr 697.

8. Dell'Osso LF, Van der Steen J, Steinman RM, Collewijn H. Foveation strategy in congenital nystagmus. 1. Fixation. Doc Ophthalmol 1992;79:1-23.

9. Abadi RV, Pascal E, Worfolk R, Whittle J. Retinal fixation behaviour in human albinos. Optom Vis Sci 1989;66:276-80.

10. Dickinson CM. The elucidation and use of the effect of near fixation in congenital nystagmus. Ophthalmic Physiol Optics 1986;6:303-11.

11. Abadi RV, Carden D, Simpson J. A new treatment for congenital nystagmus. Br J Ophthalmol 1980;64:2-6.

12. Dell'Osso LF, Leigh RJ, Daroff RB. Suppression of congenital nystagmus by cutaneous stimulation. Neuro-Ophthalmology 1991;11:173-5.

13. Anderson JR. Causes and treatment of congenital eccentric nystagmus. Br J Ophthalmol 1953;37:267-81.

14. Goto N. A study of optic nystagmus by the electrooculogram. Acta Soc Ophthalmol Jpn 1954;58:851-65.

15. Kestenbaum A. Nouvelle operation de nystagmus. Bull Soc Ophtalmol Fr 1953;6:599-602.

16. Zubcov AA, Stark N, Weber A, Wizov SS, Reinecke RD. Improvement of visual acuity after surgery for nystagmus. Ophthalmology 1993;100:1488-97.

17. Dell'Osso LF, Flynn JT. Congenital nystagmus surgery: a quantitative evaluation of the effects. Arch Ophthalmol 1979;97:462-9.

18. Abadi RV, Whittle JP. Surgery and compensatory head posture in congenital nystagmus: a longitudinal study. Arch Ophthalmol 1992;110:632-5.

19. Dell'Osso LF. Extra-ocular muscle tenotomy, dissection, and suture: a hypothetical therapy for congenital nystagmus. J Pediatr Ophthalmol Strabismus 1998;35:232-3. 